\title{
GLOBAL KINETICS FOR $n$-HEPTANE IGNITION AT HIGH PRESSURES
}

\author{
U. C. MÜLLER AND N. PETERS \\ Institut für Technische Mechanik \\ Rheinisch-Westfälische Technische Hochschule Aachen \\ Federal Republic of Germany \\ AND \\ A. LIÑÁN \\ Dpto. Motopropulsion y Thermofluidoninamica \\ Universidad Politècnica de Madrid, Spain
}

\begin{abstract}
A kinetic mechanism of 1011 elementary reactions with 171 chemical species for $n$-heptane ignition is analysed and reduced to 4 global steps with adjusted rate coefficients to describe ignition at pressures around $40 \mathrm{~atm}$. Two of these steps account for the high temperature branch and the other two for the low temperature branch of the ignition mechanism. The ignition delay time passes through a negative temperature dependence during the transition between the two branches. This is accounted for by the reversible third reaction step, which models the first and second $\mathrm{O}_{2}$-addition in the degenerated chain branching mechanism at low temperatures. Ignition delay times calculated with the adjusted 4-step model are compared to those from the detailed kinetics and experimental data. Finally the 4-step mechanism is analysed by asymptotic methods and explicit ignition delay time formulas are derived.
\end{abstract}

\section{Introduction}

Auto-ignition plays a central part in many practical combustion systems burning hydrocarbon fuels. One example is the ignition of the fuel spray in a Diesel engine, another is the auto-ignition of the end gas in a spark ignition engine. While a short ignition delay time is desirable in the Diesel engine, it is undesirable in the spark ignition engine since it may lead to the onset of engine knock and therefore to knock damage.

Ignition of higher hydrocarbon fuel typically exhibits two distinctly different regimes: ${ }^{1,2,3}$

1. the high temperature regime where the fuel is rapidly decomposed into small $\mathrm{C}_{2^{-}}$and $\mathrm{C}_{1}$-hydrocarbons, which are subsequently oxidized;

2. the low temperature regime where the fuel is oxidized by $\mathrm{O}_{2}$-addition in a degenerated chain branching.

Rather detailed mechanisms have been proposed to model the ignition delay times of fuels like $n$-heptane and iso-octane over a large temperature range. ${ }^{1,4,5,6}$ Some reduced ad-hoc models also have been proposed to describe the basic chemical interactions in a conceptually more accessable form. $4,7,8,9$ Only recently, however, reliable experimental data for $n$-heptane ignition have been produced by experiments in a large shock tube with sufficiently large residence times of an undisturbed mixture behind the reflected shock. ${ }^{10}$ These data were used to adjust the elementary kinetic parameters, in particular those of the low temperature chemistry. ${ }^{3,11}$ This led to a reaction mechanism of 1011 elementary reactions with 171 chemical species for the $n$-heptane ignition chemistry. Figure 1 shows that the full kinetics reproduce the ignition delay times of the experimental data ${ }^{10}$ quite well. This mechanism was analysed with respect to the sensitivity of ignition delay times of the individual reactions.

The high temperature oxidation proceeds from the attack on the fuel by $\mathrm{H}, \mathrm{OH}$ and $\mathrm{HO}_{2}$ radicals to form $n$-heptyl radicals and through the break-up of these into $\mathrm{C}_{2} \mathrm{H}_{4}, \mathrm{CH}_{3}$ and $\mathrm{H}$ radicals. These are oxidized by reactions of the well-known $\mathrm{C}_{1}-\mathrm{C}_{2}$ chemistry. An essential feature of low temperature ignition of aliphatic hydrocarbons is the existence of a negative temperature dependence of ignition delay times in the intermediate temperature range as seen in Fig. 1. The chemistry for temperatures lower than $1000 \mathrm{~K}$ is characterized by degenerated chain branching which may be illustrated by the following sequence of reaction steps:

$$
\begin{aligned}
\mathrm{RH}+\mathrm{OH} & \rightarrow \mathrm{R}+\mathrm{H}_{2} \mathrm{O} \\
\mathrm{R}+\mathrm{O}_{2} & \rightleftharpoons \mathrm{RO}_{2}
\end{aligned}
$$

(first $\mathrm{O}_{2}$-addition) 


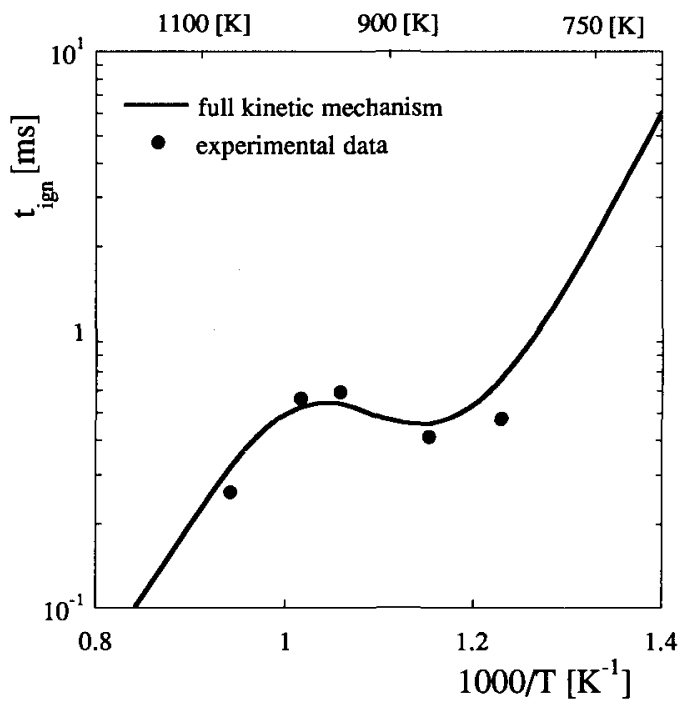

FIG. 1. Comparison of calculated ignition delay times of the full kinetics with experimental data ${ }^{10}$ at $40 \mathrm{~atm}$ and a stoichiometric $n$-heptane/air mixture.

$$
\begin{aligned}
& \mathrm{RO}_{2} \rightarrow \mathrm{R}^{\prime} \mathrm{O}_{2} \mathrm{H} \\
& \text { (internal } \mathbf{H} \text {-abstraction) } \\
& \mathrm{R}^{\prime} \mathrm{O}_{2} \mathrm{H}+\mathrm{O}_{2} \rightleftharpoons \mathrm{O}_{2} \mathrm{R}^{\prime} \mathrm{O}_{2} \mathrm{H} \\
& \text { (second } \mathrm{O}_{2} \text {-addition) } \\
& \mathrm{O}_{2} \mathrm{R}^{\prime} \mathrm{O}_{2} \mathrm{H} \rightarrow \mathrm{HO}_{2} \mathrm{R}^{\prime \prime} \mathrm{O}_{2} \mathrm{H} \\
& \text { (internal } \mathrm{H} \text {-abstraction) } \\
& \mathrm{HO}_{2} \mathrm{R}^{\prime \prime} \mathrm{O}_{2} \mathrm{H} \rightarrow \mathrm{HO}_{2} \mathrm{R}^{\prime \prime} \mathrm{O}+\mathrm{OH} \\
& \text { (chain propagation) } \\
& \mathrm{HO}_{2} \mathrm{R}^{\prime \prime} \mathrm{O} \rightarrow \mathrm{OR}^{\prime \prime} \mathrm{O}+\mathrm{OH}
\end{aligned}
$$$$
\text { (chain branching) }
$$

For $n$-heptane $\mathrm{R}$ is represented by $\mathrm{C}_{7} \mathrm{H}_{15}, \mathrm{R}^{\prime}=$ $\mathrm{C}_{7} \mathrm{H}_{14}$ and $\mathrm{R}^{\prime \prime}=\mathrm{C}_{7} \mathrm{H}_{13}$. The competition of the reverse reaction of the first $\mathrm{O}_{2}$-addition with the subsequent internal $\mathrm{H}$-abstraction is the key to understanding the negative temperature dependence of ignition delay.

\section{The Adjusted Four-Step Mechanism}

Since a large number of the intermediate species remains at low concentrations, it is possible to introduce steady state assumptions for these intermediates and thus to derive a systematically reduced mechanism. ${ }^{12}$ Such a mechanism results in approximately 16 global reactions, which are controlled by the original elementary kinetic rate data. ${ }^{13}$
Here, however, we want to retain only the essential information from the chemistry and present a 4 -step model with adjusted rate coefficients, which is written as

$$
\begin{array}{r}
\mathrm{F} \stackrel{\mathrm{I}}{\stackrel{2}{\rightarrow} \mathrm{X}} \\
\mathrm{X}+11 \mathrm{O}_{2} \underset{2}{\rightarrow} \mathrm{P} \\
\mathrm{F}+2 \mathrm{O}_{2} \underset{3 b}{\stackrel{3 f}{\rightleftharpoons}} \mathrm{I} \\
\mathrm{I}+9 \mathrm{O}_{2} \stackrel{4}{\rightarrow} \mathrm{P}
\end{array}
$$

Here $\mathrm{F}$ stands for the fuel, with $\mathrm{F}={ }^{n}-\mathrm{C}_{7} \mathrm{H}_{16} . \mathrm{X}$ and I represent the combined intermediates, where $\mathrm{X}=3 \mathrm{C}_{2} \mathrm{H}_{4}+\mathrm{CH}_{3}+\mathrm{H}$ and $\mathrm{I}=\mathrm{HO}_{2} \mathrm{R}^{\prime \prime} \mathrm{O}+\mathrm{H}_{2} \mathrm{O}$. $\mathrm{P}$ represents a combination of the products, with $\mathrm{P}$ $=7 \mathrm{CO}_{2}+8 \mathrm{H}_{2} \mathrm{O}$.

The first two reactions correspond to a two-step high temperature scheme containing an endothermic fuel decomposition into small hydrocarbons and the exothermic oxidation of these into the final combustion products. The last two steps represent the degenerated chain branching mechanism discussed above. Steady state assumptions for all intermediates in this chain mechanism up to $\mathrm{HO}_{2} \mathrm{R}^{\prime \prime} \mathrm{O}$ lead to the third global step of the model. The fourth step contains the chain branching and the oxidation to the combustion products. Only the third reaction is considered to be reversible. The activation energy of the backward reaction $3 b$ is assumed much larger than that of the forward reaction $3 f$. Therefore, at low temperatures the backward reaction $3 b$ is unimportant. However, at temperatures around $830 \mathrm{~K}$ and higher, the backward reaction dominates over the forward reaction and thereby decreases the relative importance of reactions 3 and 4 in the mechanism. This explains the transition from the low temperature to the high temperature branch. The rate coefficients and the thermodynamic data to be used are given below.

In writing the conservation equations for this mechanism we shall assume, for the simplicity of the presentation, that the mean molecular mass and the specific heat at constant pressure are constant. Thus the conservation equations for the mole fractions $X_{F}, X_{X}, X_{1}$ and $X_{O}$ of $F, X, I$ and $\mathrm{O}_{2}$ take the form:

$$
\begin{aligned}
& \frac{d}{d t} X_{\mathrm{F}}=-k_{1} X_{\mathrm{F}}-k_{3 f} X_{\mathrm{F}} X_{\mathrm{O}}+k_{3 b} X_{\mathrm{I}} \\
& \frac{d}{d t} X_{\mathrm{X}}=k_{\mathrm{I}} X_{\mathrm{F}}-k_{2} X_{\mathrm{X}} X_{\mathrm{O}} \\
& \frac{d}{d t} X_{\mathrm{I}}=k_{3 f} X_{\mathrm{F}} X_{\mathrm{O}}-k_{3 b} X_{\mathrm{I}}-k_{4} X_{\mathrm{I}} X_{\mathrm{O}} \\
& \frac{d}{d t}\left(X_{\mathrm{O}}-11 X_{\mathrm{F}}-11 X_{\mathrm{X}}-9 X_{\mathrm{I}}\right)=0
\end{aligned}
$$


The energy conservation equation can be written in the form

$$
\begin{aligned}
\frac{d}{d t} T= & T_{1} k_{1} X_{\mathrm{F}}+T_{2} k_{2} X_{\mathrm{X}} X_{\mathrm{O}} \\
& +T_{3}\left(k_{3 f} X_{\mathrm{F}} X_{\mathrm{O}}-k_{3 b} X_{\mathrm{I}}\right)+T_{4} k_{4} X_{\mathrm{I}} X_{\mathrm{O}}
\end{aligned}
$$

Here the temperatures $T_{1}, T_{2}, T_{3}$ and $T_{4}$ take the values $-20400 \mathrm{~K}, 149800 \mathrm{~K}, 1550 \mathrm{~K}$ and 127850 $K$. They were obtained by dividing the reacting enthalpies of the four different reactions by the constant pressure specific heat of the mixture, which was assumed to have a constant value of $34.8(\mathrm{~J} /$ mol K). Notice that $T_{1}+T_{2}=T_{3}+T_{4}$. Equations (1)-(3) and (5) can be combined to yield the conservation equation

$$
\begin{aligned}
\frac{d}{d t}\left\{T+\left(T_{1}+T_{2}\right)\right. & X_{\mathrm{F}}+T_{2} X_{\mathrm{X}} \\
& \left.+\left(T_{3}+T_{4}\right) X_{\mathrm{f}}+T_{4} X_{\mathrm{I}}\right\}=0
\end{aligned}
$$

The reaction constants appearing in Eqs. (1)-(3), have dimensions $\mathrm{s}^{-1}$, and are given by

$$
\begin{aligned}
k_{1} & =A_{1} \mathrm{e}^{-E_{1} / R T}, \quad=\frac{p}{R T} A_{2} \mathrm{e}^{-E_{2} / R T}, \\
k_{3 f} & =\frac{p}{R T} A_{3 f} \mathrm{e}^{-E_{3 f} / R T} \quad k_{3 b}=A_{3 b} \mathrm{e}^{-E_{3 b} / R T}, \\
k_{4} & =\frac{p}{R T} A_{4} \mathrm{e}^{-E_{4} / R T}
\end{aligned}
$$

The factor $p / R T$ in some of the reaction constants represents the number of moles per unit volume. The values for the activation temperatures $E / R$, and for the pre-exponential factors $A$, are

$$
\begin{aligned}
& E_{1} / R=21650 \mathrm{~K}, \quad E_{3 f} / R=E_{1}, \quad E_{2}=E_{1} / 3 \\
& E_{3 b} / R=37285 \mathrm{~K}, \quad E_{4} / R=13230 \mathrm{~K}
\end{aligned}
$$

and

$$
\begin{aligned}
A_{1} & =1 \cdot 10^{10}\left(\mathrm{~s}^{-1}\right) \\
A_{3 b} & =4 \cdot 10^{22}\left(\mathrm{~s}^{-1}\right) \\
A_{2} & =2 \cdot 10^{12}\left(\mathrm{~cm}^{3} \mathrm{~mol}^{-1} \mathrm{~s}^{-1}\right) \\
A_{3 f} & =3 \cdot 10^{18}\left(\mathrm{~cm}^{3} \mathrm{~mol}^{-1} \mathrm{~s}^{-1}\right) \\
A_{4} & =5 \cdot 10^{13}\left(\mathrm{~cm}^{3} \mathrm{~mol}^{-1} \mathrm{~s}^{-1}\right)
\end{aligned}
$$

Equations (1)-(4) and (6) were integrated numerically using the initial conditions

$t=0 ; \quad X_{\mathrm{F}}=X_{\mathrm{F}, 0} \quad X_{\mathrm{O}}=X_{\mathrm{O}, 0}$,

$$
X_{\mathrm{X}}=X_{\mathrm{I}}=0, \quad T=T_{0}
$$

The resulting ignition delay times are compared to those of a calculation using the full kinetics in Fig. 2. All calculations were made for a pressure of 40 atm and a stoichiometric fuel/air mixture. In general the 4-step mechanism agrees well with the full kinetic mechanism. The maximum error is less than $20 \%$ in the region of about $850 \mathrm{~K}$. At different equivalence ratios ignition time depends more on the mole fraction of the fuel $X_{\mathrm{F}, 0}$ than on the mole fraction of the oxygen. In Fig. 3 the results of cal-

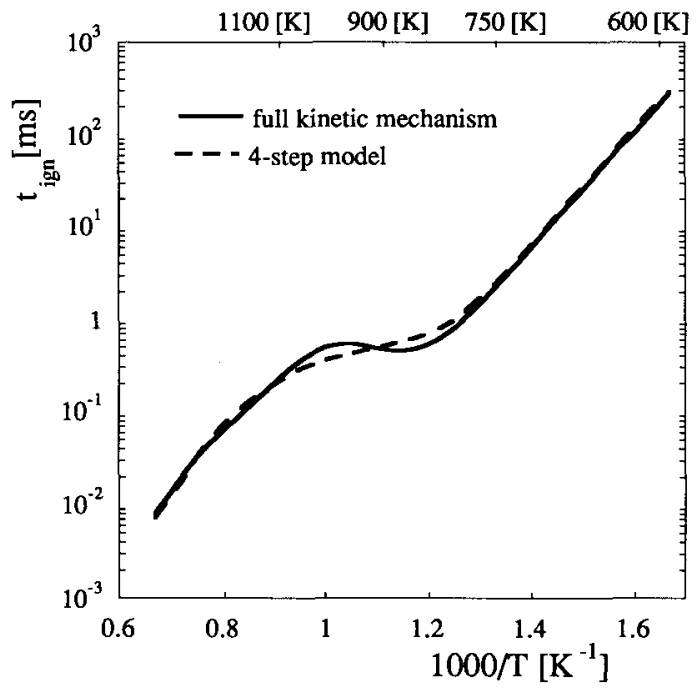

FIG. 2. Comparison of calculated ignition delay times of the full kinetics and those from the 4-step model at $40 \mathrm{~atm}$ and a stoichiometric $n$-heptane/air mixture.

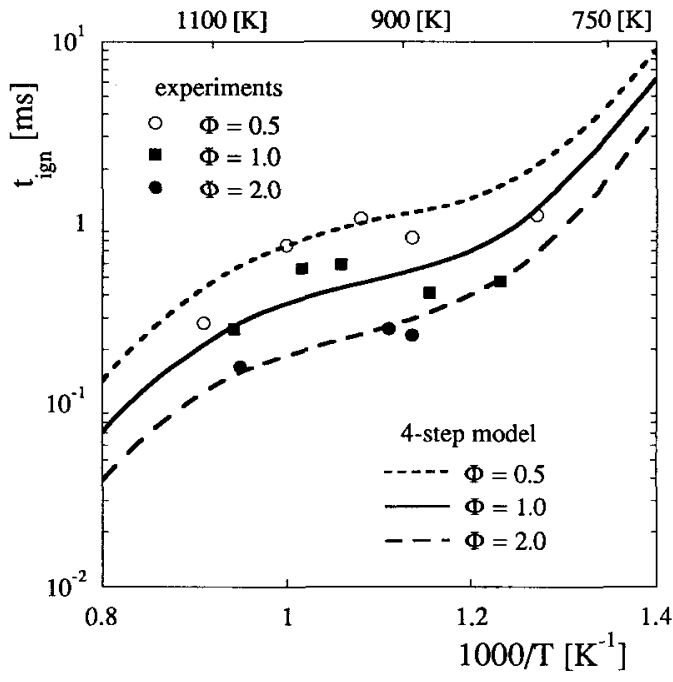

FIG. 3. Comparison of calculated ignition delay times of the 4-step model with experiments ${ }^{10}$ at 40 atm and different fuel/air equivalence ratios. 
culations for different equivalence ratios are compared to experiments. Ignition delay times are larger for lean mixtures and lower for rich mixtures. The 4-step model also agrees well with the experimental data. ${ }^{10}$
Negative Temperature Dependence Branch:

Let us, for the moment, neglect the effects of reactions 1 and 2; we are left with the low temperature scheme

$$
\begin{aligned}
& \mathrm{F}+2 \mathrm{O}_{2} \underset{3 b}{\stackrel{3 f}{\rightleftharpoons}} \mathrm{I} \\
& \mathrm{I}+9 \mathrm{O}_{2} \stackrel{4}{\rightarrow} \mathrm{P}
\end{aligned}
$$

The conservation equations in this case simplify to

$$
\begin{aligned}
\frac{d}{d t} X_{\mathrm{F}} & =-k_{3 f} X_{\mathrm{F}} X_{\mathrm{O}}+k_{3 b} X_{\mathrm{I}} \\
\frac{d}{d t} X_{\mathrm{I}} & =k_{3 f} X_{\mathrm{F}} X_{\mathrm{O}}-k_{3 b} X_{\mathrm{I}}-k_{4} X_{\mathrm{I}} X_{\mathrm{O}} \\
X_{\mathrm{O}}-11 X_{\mathrm{F}}-9 X_{\mathrm{I}} & =X_{\mathrm{O}, 0}-11 X_{\mathrm{F}, 0} \\
T+\left(T_{3}+T_{4}\right) X_{\mathrm{F}}+T_{4} X_{\mathrm{I}} & =T_{0}+\left(T_{3}+T_{4}\right) X_{\mathrm{F}, 0}
\end{aligned}
$$

\section{Asymptotic Analysis of the Ignition Process}

In order to understand the interaction between the different reactions of the 4-step mechanism, it is useful to compare the magnitude of the reaction rates in an Arrhenius diagram. Estimates of the reaction rates in Eqs. (1)-(3) can be obtained using values of $X_{\mathrm{F}}, X_{\mathrm{O}}$ and $T$ equal to their initial values $X_{\mathrm{F}, 0}, X_{\mathrm{O}, 0}$ and $T_{0}$, and values for the mole fractions $X_{X}$ and $X_{I}$ of the intermediates equal to $X_{F, 0}$.

The reaction rates, if we leave aside a factor $X_{F, 0}$ to obtain a measure of the inverse of the reaction times of the five reactions, are

$$
k_{1}, k_{2} X_{O, 0}, k_{3 f} X_{O, 0}, k_{3 b} \text {, and } k_{4} X_{O, 0}
$$

where the reaction rates of the reactions $2,3 f$ and 4 include a factor $p / R T$, while the other rates are independent of the pressure.

Thus, if we consider as an example a stoichiometric mixture of $n$-heptane with air $\left(X_{\mathrm{F}, 0}=0.0187\right.$ and $X_{0,0}=0.2061$ ) at a pressure of $40 \mathrm{~atm}$, we obtain the reaction rates shown in Fig. 4 as functions of $T_{0}$. Notice that these reaction rates are shifted upwards or downwards if the factor $p X_{\mathrm{O}, 0}$ appearing in the rates of the reactions $2,3 f$, and 4 is changed.

The reaction times for the five reactions are seen to differ in order of magnitude; their ratios change with $T_{0}$, changing from large to small or vice versa when $T_{0}$ passes through cross-over temperatures. The reaction rate of the first reaction is very small compared to the rate of the third reaction in the temperature range of interest in Diesel engine ignition. Thus the low temperature reaction path corresponding to reactions 3 and 4 appears to be favourable.
In Fig. 4 we see that for temperatures above 800 $\mathrm{K}$ the rate of reaction 4 is small compared to the rates of the two reactions 3 . Under these conditions, there are two stages in the ignition process: In a first stage, with a characteristic time determined by the reactions 3 , we can neglect the effect of reaction 4. No significant change of temperature occurs during this stage because $T_{3}$ is small compared to $T_{4}$. The consumption of oxygen during this stage is also small because the partial stoichiometric coefficient 2 is small compared to 9 . The temperature rise can only occur during the second stage,

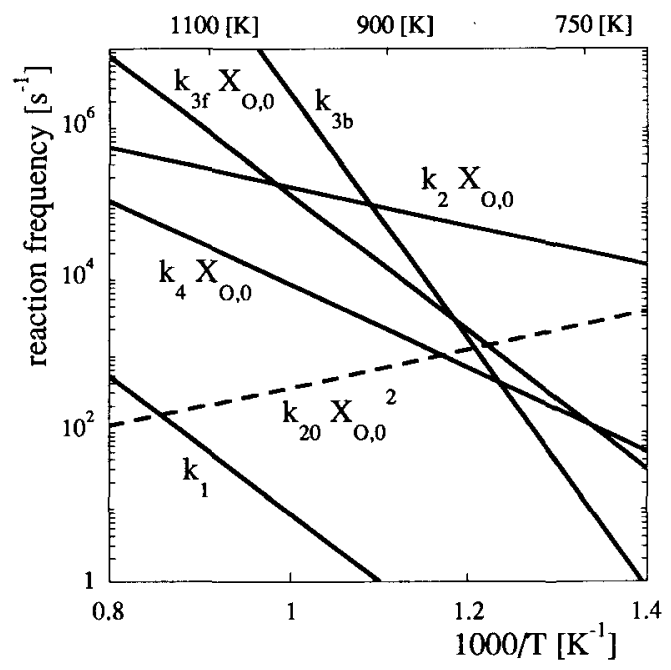

FIG. 4. Arrhenius diagram of the time scales of the different steps in the 4-step model. 
when the fast reactions 3 are in partial equilibrium. In the long second stage, when the rise in temperature will take place, Eqs. (7) and (8) simplify to

$$
\begin{aligned}
k_{3 f} X_{O} X_{\mathrm{F}} & =k_{3 b} X_{\mathrm{I}} \\
\frac{d}{d t}\left(X_{\mathrm{I}}+X_{\mathrm{F}}\right) & =\frac{d}{d t} X_{\mathrm{S}}=-k_{4} X_{\mathrm{I}} X_{\mathrm{O}}
\end{aligned}
$$

If we define $X_{S}=X_{I}+X_{\mathrm{F}}$, the mole fraction of the pool formed by $I$ and F, then Eq. (11) leads to

$$
X_{\mathrm{I}}=X_{\mathrm{S}} \frac{K X_{O}}{1+K X_{O}}
$$

where $K$ is the equilibrium constant of the third reaction

$$
K=\frac{k_{3 f}}{k_{3 b}}=\frac{p}{R T} \frac{A_{3 f}}{A_{3 b}} \mathrm{e}^{\left(E_{3 b}-E_{3 f}\right) / R T}
$$

Thus Eq. (12) becomes

$$
\frac{d}{d t} X_{\mathrm{S}}=-k_{4} \frac{K X_{\mathrm{O}}}{1+K X_{\mathrm{O}}} X_{\mathrm{O}} X_{\mathrm{S}}
$$

Since $T_{3}$ is small compared to $T_{3}+T_{4}$ the temperature equation may be written as

$$
\frac{d}{d t} T=\left(T_{3}+T_{4}\right) k_{4} \frac{K X_{O}}{1+K X_{O}} X_{O} X_{S}
$$

Equations (15) and (16) are to be solved with the relations (9) and (10) and the initial condition

$$
t=0: \quad X_{\mathrm{S}}=X_{\mathbf{F}, 0}, \quad T=T_{0}
$$

For values of $T$ larger than the cross-over temperature of approximately $830 \mathrm{~K}, K X_{\mathrm{O}}$ becomes small compared to 1 . In this case the reverse reaction 3 is so fast that the concentration of I cannot grow: $X_{\mathrm{I}} \ll 1$. Then $X_{\mathrm{S}}=X_{\mathrm{F}}$ and thus Eq. (15) simplifies to

$$
\frac{d}{d t} X_{\mathrm{F}}=-k_{4} K X_{\mathrm{O}}^{2} X_{\mathrm{F}}
$$

corresponding to the overall kinetic scheme

$$
\mathrm{F}+11 \mathrm{O}_{2} \rightarrow \mathrm{P}
$$

resulting from the steady state approximation for I. Note that the resulting expression for the overall rate is of second order with respect to $X_{\mathrm{O}}$ and of first order with respect to $X_{F}$. The reaction con- stant

$$
k_{4} K=\left(\frac{p}{R T}\right)^{2} \frac{A_{3 f}}{A_{3 b}} A_{4} \mathrm{e}^{-\left(E_{4}+E_{3 f}-E_{3 h}\right) / R T}
$$

is associated with a negative activation temperature

$$
\left(E_{3 f}+E_{4}-E_{3 b}\right) / R=-2370[\mathrm{~K}]
$$

In summary, for temperatures significantly above $830 \mathrm{~K}$, the overall rate of fuel consumption is given by

$$
\frac{d}{d t} X_{\mathrm{F}}=-\left(\frac{p}{R T}\right)^{2} 3.75 \cdot 10^{9} \mathrm{e}^{2370 / T} X_{O}^{2} X_{\mathrm{F}}
$$

This rate is seen to decrease with increasing temperature, explaining the increase of the ignition time above $900 \mathrm{~K}$. The reaction frequency

$$
k_{20} X_{O, 0}^{2}=3.75 \cdot 10^{9} \mathrm{e}^{2370 / T}\left(\frac{p}{R T}\right)^{2} X_{O, 0}^{2}
$$

which is a measure of the inverse of the reaction time, is also plotted in Fig. 4 with a dashed line.

\section{High Temperature Branch:}

For temperatures larger than $1180 \mathrm{~K}$ the rate of fuel consumption by reactions 3 and 4 , determined by (20), becomes smaller than the rate associated with reaction 1 . Notice that at these high temperatures reaction 2 is very fast compared to reaction $\mathrm{I}$ and thus $\mathrm{X}$ follows the steady state approximation, being consumed as fast as it is produced. Reactions 1 and 2 can be replaced by the overall reaction

$$
\mathrm{F}+11 \mathrm{O}_{2} \rightarrow \mathrm{P}
$$

with the rate

$$
\frac{d}{d t} X_{\mathrm{F}}=-k_{\mathrm{l}} X_{\mathrm{F}}
$$

Combining the effects of the two reaction paths the rate of fuel consumption for the entire temperature range (temperatures between $1500 \mathrm{~K}$ and $850 \mathrm{~K}$ ) can with Eq. (17) and (22) be written as

$$
\frac{d}{d t} X_{\mathrm{F}}=-k_{1} X_{\mathrm{F}}-k_{4} K X_{\mathrm{F}} X_{\mathrm{O}}^{2}
$$

Notice that the reaction rate dependence given by (23) leads to a minimum around $1180 \mathrm{~K}$. With $T_{1}$ $+T_{2}=T_{3}+T_{4}$ the corresponding temperature equation is 


$$
\frac{d}{d t} T=\left(T_{1}+T_{2}\right)\left(k_{1} X_{F}+k_{4} K X_{\mathrm{F}} X_{\mathrm{O}}^{2}\right)
$$

\section{Low Temperature Branch:}

For temperatures lower than $800 \mathrm{~K}$, reaction 3 is no longer in partial equilibrium and $X_{I}$ is not determined by Eq. (11). However, the last term in Eq. (8) is small compared to either the first term (for low temperatures) or the second term (for temperatures around $850 \mathrm{~K}$ ) and may therefore be neglected. Again there is a two-stage ignition process, where the fuel is partly converted to the intermediate I in the first stage. As in the negative temperature dependence branch, no significant heat release occurs during this stage. The subsequent consumption of I during the second stage is governed by the exothermic reaction 4 and leads to thermal runaway. Combining Eqs. (7) and (8) leads to the solution

$$
X_{\mathrm{F}}+X_{\mathrm{I}}=X_{\mathrm{F}, 0}
$$

Then Eq. (7) becomes

$$
\frac{d}{d t} X_{\mathrm{F}}=-\left(k_{3 f} X_{\mathrm{O}}+k_{3 b}\right) X_{\mathrm{F}}+k_{3 b} X_{\mathrm{F}, 0}
$$

which may be integrated to yield

$$
X_{\mathrm{F}}=X_{\mathrm{F}, 0}\left[\mathrm{e}^{-k t}+\frac{1}{1+K X_{\mathrm{O}, 0}}\left(1-e^{-k t}\right)\right]
$$

where $k=k_{3 f} X_{\mathrm{O}, 0}+k_{3 b}$, assuming constant temperature and $X_{\mathrm{O}}=X_{\mathrm{O}, 0}$. Since $\mathrm{T}_{4} \gg \mathrm{T}_{3}$ we cannot, however, neglect the heat release due to reaction 4. The temperature equation becomes in this limit

$$
\frac{d}{d t} T=T_{4} k_{4} X_{\mathrm{O}}\left(X_{\mathrm{F}, 0}-X_{\mathrm{F}}\right)
$$

Ignition, therefore, is due to the consumption of small amounts of $X_{\mathrm{I}}$ governed by reaction 4 .

\section{Calculation of Ignition Delay Times}

At first only the temperature range between 1500 and $850 \mathrm{~K}$ is of interest. Due to the large exothermicity of the reactions, small changes in the fuel and oxygen concentration are sufficient to increase the temperature significantly. Accounting for the fact that the activation energy $E_{1}$ is large and that $\left(E_{3 f}\right.$ $\left.-E_{3 b}+E_{4}\right) / R T_{0}$ is of order unity an expansion of the temperature is given as

$$
T=T_{0}+\frac{R T_{0}^{2}}{E_{1}} \varphi
$$

and neglecting the reactant consumption in Eq. (24) by setting $X_{\mathrm{F}}=X_{\mathrm{F}, 0}$ and $X_{\mathrm{O}}=X_{\mathrm{O}, 0}$ one obtains

$$
\frac{d}{d t} \varphi=\frac{1}{t_{1}} \mathrm{e}^{\varphi}+\frac{1}{t_{2}}
$$

with the initial condition $\varphi(0)=0$. At the ignition time $\varphi$ becomes infinite

$$
t_{i g n}=t_{2} \ln \left(1+t_{1} / t_{2}\right)
$$

Here

$$
\begin{aligned}
\frac{1}{t_{1}}= & \left(\frac{E_{1}}{R T_{0}} \frac{T_{1}+T_{2}}{T_{0}} X_{\mathrm{F}, 0}\right) A_{1} \mathrm{e}^{-E_{1} / R T_{0}} \\
\frac{1}{t_{2}}= & \left(\frac{E_{1}}{R T_{0}} \frac{\mathrm{T}_{1}+\mathrm{T}_{2}}{T_{0}} X_{\mathrm{F}, 0}\right) A_{4} \frac{A_{3 f}}{A_{3 b}} \\
& \cdot \mathrm{e}^{-\left(E_{3 f}-E_{3 b}+E_{4}\right) / R T_{0}}\left(\frac{p}{R T_{0}} X_{\mathrm{O}, 0}\right)^{2}
\end{aligned}
$$

For initial temperatures $T_{0}$ such that $K X_{0,0} \ll 1$ the ignition time is calculated according Eq. (31) together with the relations (32) and (33).

For temperatures significantly below $850 \mathrm{~K}$ the ignition time has to be calculated with the relations (27) and (28). Introducing the time variable

$$
\begin{aligned}
\tau & =\frac{K X_{\mathrm{O}, 0}}{1+K X_{O, 0}} \int_{0}^{t}\left(1-\mathrm{e}^{-k t}\right) d t \\
& =\frac{K X_{0,0}}{1+K X_{O, 0}}\left[t-\frac{1}{k}\left(1-\mathrm{e}^{-k t}\right)\right]
\end{aligned}
$$

Eq. (28) may be written as

$$
\frac{d}{d \tau} T=T_{4} k_{4} X_{O} X_{\mathrm{F}, 0}
$$

Thermal ignition occurs at

$$
\frac{1}{\tau_{\text {ign }}}=\frac{E_{4}}{R T_{0}} \frac{T_{4}}{T_{0}} X_{\mathrm{F}, 0} X_{\mathrm{O}, 0} A_{4} \mathrm{e}^{-E_{4} / R T_{0}} \frac{p}{R T_{0}}
$$

Eq. (34) may be inverted and approximated by a composite form satisfying small and large times as 


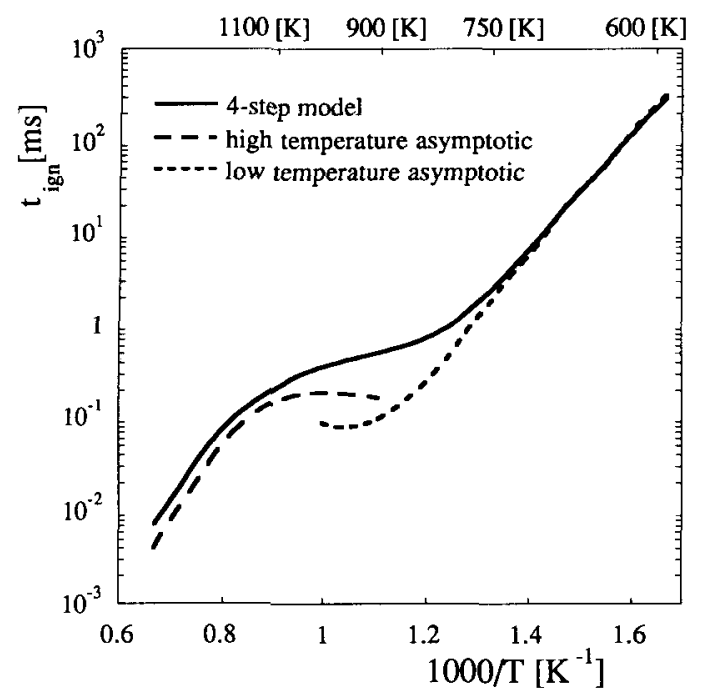

FIG. 5. Comparison of calculated ignition delay times of the 4-step model and asymptotic solutions at $40 \mathrm{~atm}$ and a stoichiometric $n$-heptane/air mixture.

$$
t=\frac{1+K X_{\mathrm{O}, 0}}{K X_{\mathrm{O}, 0}} \tau+\sqrt{\frac{2 \tau}{k} \frac{1+K X_{\mathrm{O}, 0}}{K X_{\mathrm{O}, 0}}}
$$

Introducing $\tau=\tau_{i g n}$ from Eq. (36) into Eq. (37) leads to the ignition time $t_{i g n}$ for the low temperature branch.

The resulting ignition times for the high temperature branch Eq. (31) and the low temperature branch Eq. (37) are compared to the numerical solution of the 4-step model in Fig. 5. The two asymptotic solutions describe qualitatively the general features of the full kinetic mechanism and both show the negative temperature dependence of ignition delay in the intermediate temperature range. The differences between the high temperature asymptotics and the 4-step numerical solution at temperatures above $1200 \mathrm{~K}$ are caused by the steady state assumption of the intermediate specie $X$ and thereby by the neglection of the endothermic effects of the first reaction. At temperatures lower than $800 \mathrm{~K}$ the agreement of the low temperature asymptotics and the 4-step model is quite good. In the intermediate temperature range there is an interaction between the different regimes. The numerical solution does not separate the influence of the high and low temperature branch in the same way as the two asymptotic descriptions. This is the reason why the negative temperature dependence of the numerical 4 -step solution in the intermediate range is missing.

\section{Conclusion}

A 4-step model with adjusted rate coefficients was derived that describes ignition at pressures around $40 \mathrm{~atm}$. Ignition delay times calculated with the 4step model and the full kinetics are in agreement with experiments. The maximum error in ignition delay between the two kinetic formulations is less than $20 \%$. The dependence of ignition delay times on the equivalence ratio, calculated with the 4-step model, is satisfactory and also in agreement with experiments.

The mathematical structure of the 4-step mechanism has been studied by asymptotic analysis. The high temperature and the low temperature branch were analysed separately. Both asymptotics display a negative temperature dependence in the intermediate temperature range, thereby illustrating that the 4-step mechanism contains the general features of the full kinetic mechanism.

\section{Acknowledgement}

This work was sponsored by the Commission of European Communities, by the National Swedish Board for Industrial and Technical Development (NUTEK) and by the Joint Research Council of European car manufacturers within the IDEA program.

\section{REFERENCES}

1. Westbrook, C. K., Warnatz, J. and Pitz, W. J.: Twenty-Second Symposium (International) on Combustion, p. 893, The Combustion Institute, 1989.

2. Pollard, R. T.: Comprehensive Chemical Kinetics, (Bamford, C. H. and Tipper, C. F. H., Ed.), Vol 17, p. 249, American Elsevier, 1977.

3. Chevalier, C., Louessard, P., Múller, U. C. and Warnatz, J.: Int. Symp. on Diagnostics and Modeling of Combustion in Internal Engines, COMODIA 90, Kyoto The Japan Society of Mechanical Engineers, 1990.

4. Cowart, J. S., Keck, J. C., Heywood, J. B., Westbrook, C. K. AND Pitz, W. J.: TwentyThird Symposium (International) on Combustion, p. 1055, The Combustion Institute, 1991.

5. Westbrook, C. K., Pitz, W. J. and Leppard, W. R.: SAE paper No. 912314 (1991).

6. Pitz, W. J., Westbrook, C. K. and Leppard, W. R.: SAE paper No. 912315 (1991).

7. Coats, C. M. and Williams, A.: Seventeenth Symposium (International) on Combustion, p. 611, The Combustion Institute, 1979.

8. Cox, R. A. and Cole, J. A.: Combust. Flame 60, 109, 1985. 
9. Halstead, M. P., Kirsch, L. J. and Quinn, C. P.: Combust. and Flame 30, 45, 1977.

10. Ciezki, H. And Adomeit, G.: Shock tube investigation of self-ignition of fuel/air mixtures under engine conditions, to appear in Combust. Flame, 1992.

11. Warnatz, J.: Private communication, 1991.

12. Peters, N.: Systematic Reductions of Flame
Kinetics; Principles and Details, in Progress in Astronautics and Aeronautics (KUHL, A. L., Bowen, J. R., Leyer, J. L. and Bohisov, A., Ed.), Vol 113, ISBN 0-930403-46-0, 1988.

13. Müller, U. C. AND Peters, N.: Development of reduced reaction schemes for ignition of Diesel fuels, IDEA-Programme, Internal Report, 1991.

\section{COMMENTS}

John Griffiths, University of Leeds, U.K. The numerical analysis of the 4-step scheme fails to capture the negative temperature dependence of ignition delay as shown by the computation of this full scheme and by the experimental results to which this work is matched. This qualitative flaw may be traced to the model itself. Ignition is brought about entirely by thermal feedback. There is no chain branching in any of the steps as written or reflected in the rate parameters (by encapsulating some complex dependence of fuel concentration, for example).

The negative temperature dependence of reaction rate in hydrocarbon oxidation originates in a kinetic interaction of the general structure,

$$
\text { non-branching } \leftarrow \mathrm{R}+\mathrm{O}_{2} \rightleftarrows \mathrm{RO}_{2} \rightarrow \text { branching, }
$$

as acknowledged in the introduction. However, this fundamental chain interaction cannot then be disregarded if reduced schemes are to capture correctly the features of hydrocarbon oxidation throughout the low and intermediate temperature range.

One rigorous test lies in computations of reaction rate performed under isothermal conditions. The model behaviour must show the classical "s," the shape of fuel consumption rate vs. ambient temperature. I do not believe the 4-step model would show such behaviour, but I urge the authors to try this. Of course, thermal feedback is an additional (but definitely not exclusive) ingredient of the chainthermal interaction that governs the complexity of two-stage ignition (and also oscillatory cool flames in other circumstances).

Author's Reply. We agree that in this ad-hoc-4step model, chain branching is not retained. However, this is not the reason why the numerical calculations, differently from the asymptotic analysis, do not show the negative temperature dependence. We believe that it is the thermal interaction between the two parts of the mechanisms that smears out the negative temperature dependence. In the paper we mention a systematically reduced 16 -step mechanism that uses the elementary kinetic rates. This mechanism retains the chain branching features and will be tested following your suggestions.

Dr. Christian Corre, ELF, France. I would like to know if this 4-step mechanism has already been tested in an industrial engine code (including fluid mechanics, heat transfer, . . .)?

Author's Reply. The model is being used in the framework of the IDEA collaboration within the SPEED program developed by Prof. Gosman. 